\title{
Practitioner-Generated Massage Therapy Research
}

\author{
Christopher A. Moyer, PhD \\ Assistant Professor of Psychology, University of Wisconsin-Stout, Menomonie, WI, USA.
}

At first glance, the two research studies featured in this issue of the International Journal of Therapeutic Massage and Bodywork (IJTMB) are not much alike. The study by Chunco ${ }^{(1)}$, which took top honors in the Massage Therapy Foundation's 2010 Practitioner Case Report Contest ${ }^{(2)}$, examines a single massage therapy (MT) recipient who has a distinct clinical condition, and does not rely on specialized technology for data collection. The study by Roberts ${ }^{(3)}$ uses an electromyograph, a specialized tool for assessing the electrical activity of muscles, to gather data from more than two dozen MT recipients, none of whom had a distinct clinical condition of relevance. However, these two studies are very much alike in that both are excellent examples of practitioner-generated MT research.

The key factors that make such studies possible are the curiosity and drive of the practitioners who conduct them. But these studies are also made possible by the fact that MT research is still in its early stages ${ }^{(4)}$, such that some of the most interesting and fundamental issues still have not been addressed empirically. Many of these can be researched effectively by a thoughtful and motivated practitioner who is willing to take a self-taught approach to the fundamentals of research methodology. In doing so, these pioneers bring credit to the MT profession and contribute to the knowledge base that all practitioners have to draw from.

Another benefit of practitioner-generated MT research is that it tends to maximize external validity, the degree to which research procedures accurately resemble the real-world phenomena that we wish to understand. Because all stages of the research are guided by the practitioner and, typically, are taking place in an actual clinical setting, the likelihood that such a study will differ from true clinical practice in a way that will distort the results is minimized. While this approach does come at a cost to internal validity, which is maximized in settings, such as laboratories, where researchers are able to exert control over all aspects of a study, this cost is acceptable because practitioner-generated MT research complements those other research approaches. Both internal and external validity need to be represented across the range of studies in any area of clinical research.

It is my opinion that IJTMB is the ideal outlet for practitioner-generated MT research. Aspiring practitioner-researchers can be assured that the people who review their work will be familiar not just with research methodology and statistics, but also with the way MT is actually conducted in the real world. Should your work meet the standards for publication, it will be freely available to all people interested in MT research and practice. Finally, in my role as IJTMB's Research Section Editor, I make myself available to assist practitioners with their research plans and projects. This may take several forms, depending on the practitioner's background, geographic location, and specific research topic, and could consist of helping to formalize a hypothesis, assisting with a graphic, or putting a practitioner in touch with a seasoned researcher at a nearby university or institute. Research can be daunting, but it is also uniquely rewarding. If you seek this kind of reward, do let me know if I might be able to help you in achieving it.

\section{REFERENCES}

1 Chunco R. The effects of massage on pain, stiffness, and fatigue levels associated with ankylosing spondylitis: a case study. Int J Ther Massage Bodyw. 2011;[In press].

2 Massage Therapy Foundation. Practitioner Case Report Contest. Massage Therapy Foundation Web site. http://www.massagetherapyfoundation.org/practitionercontest.html. Accessed February 25, 2011.

3 Roberts LSE. Effects of patterns of pressure application on resting EMG during massage. Int $J$ Ther Massage Bodyw. 2011; [In press].

4 Moyer CA, Dryden T, Shipwright S. Directions and dilemmas in massage therapy research: a workshop report from the 2009 North American Research Conference on Complementary and Integrative Medicine. Int J Ther Massage Bodyw. 2009; 2(2): 15-27.

\section{CONFLICT OF INTEREST NOTIFICATION}

The author declares that there are no conflicts of interest.

\section{COPYRIGHT}

Published under the CreativeCommons AttributionNonCommercial-NoDerivs 3.0 License. 